\title{
Dialektika Hadis Nabi dengan Budaya Lokal Arab
}

\author{
Abd. Halim \\ IAIN Surakarta \\ email: abdoelhalim99@gmail.com
}

\begin{abstract}
Abstrak
Perkataan Nabi Muhammad, tidak bisa dipisahkan dengan konteks situasi yang dihadapinya. Konteks tersebut bisa jadi situasi sosial, politik, ekonomi dan budaya. terdapat beberapa hadis yang harus dipahami dengan mempertimbangkan konteks sosio-kultural lokal Arab. Paper ini akan membahas tentang dialektika hadis dengan budaya lokal Arab. Dengan menggunakan pendekatan kontekstual, bisa disimpulkan bahwa terdapat hadis-hadis yang berlaku universal di samping juga terdapat hadishadis yang hanya berlaku temporal dan tentatif. Hadis-hadis temporal dan tentatif ini direkomendasikan untuk ditafsirkan ulang daripada langsung diterima dan digunakan sebagai sebuah aturan yang final.
\end{abstract}

Keywords:

hadis, budaya, Arab

\section{Pendahuluan}

Dalam banyak literatur sejarah, masyarakat Arab seringkali disebut dengan masyarakat jahiliyyah. Di dalam al-Qur'an kata ini sering disebutkan untuk menyebut karakter orang Arab yang memiliki kebiasaan yang negatif seperti permusuhan, pertumpahan darah, diskriminasi dan lain sebagainya. Namun demikian, penyebutan karakter jabiliyyah ini bukan berarti bahwa masyarakat tidak berbudaya dan tidak memiliki nilai-nilai religiositas. Ada beberapa kebudayaan yang sudah mengakar kuat di kalangan Arab yang menunjukkan bahwa mereka juga memiliki peradaban. Di antaranya adalah: 
Pertama, bahasa dan kesusastraan. Peradaban sastra di Arab pada waktu itu sudah sangat tinggi, terbukti dengan adanya pasar tahunan Ukad\%, mujinnah dan Dzul Majâz di mana para pujangga dan penyair tersohor beradu unjuk kemampuan dalam menunjukkan kehebatan mereka dalam keindahan karya satra terutama puisi dan qasîdah. (Sodiqin 2008: 47) Puisipuisi terbaik akan digantungkan di Ka'bah (mu'allaqât) di samping berhalaberhala sesembahan mereka. (Nurdin, n.d.: 29)

Kedua, tradisi keagamaan yang sudah mengakar. Dalam masalah religiositas, masyarakat Arab sudah memiliki konsep-konsep keberagamaan yang sangat beragam. Konsep-konsep animisme, totemisme sudah mengakar di dalam masyarakat. Selain itu, kepercayaan terhadap monotheisme juga sudah berkembang seperti penganut agama Yahudi, Kristen, Zoroaster, dan penganut agama hanif. (Sodiqin 2008: 47-48)

Masyarakat Arab memiliki praktik-praktik keagamaan yang sudah mengakar kuat. Di antaranya adalah: haji dan umrah, memuliakan hari Jumat, sakralisasi bulan Ramadan, mengangungkan bulan-bulan haram (Dzulqa'dah, Dzulhijjah, Muharram dan Rajab). Haji dan umrah juga biasa dilaksanakan di bulan Ramadan dengan versi yang sama-di samping ada juga perbedaan—dengan haji yang sekarang, misalnya: memakai pakaian ihram, mengumandangkan talbiyyah (dengan ungkapan syirik), melaksanakan thawaf tujuh kali dengan telanjang, menyembelih hewan qurban, sa'i, wukuf, melempar jumrah dan mencium hajar Aswad. (Sodiqin 2008: 53-54) Di kalangan Yahudi madinah juga sudah dikenal dengan puasa 'Asyura pada tanggal 10 bulan Muharram sebagai penghormatan bagi Nabi Musa yang berpuasa karena Bani Israil diselamatkan dari musuhmusuhnya di hari tersebut. Nabipun berpuasa dan menyuruh para sahabat untuk berpuasa di hari tersebut. (I. Al-Bukhari, n.d.)

Artikel ini akan membahas pola hubungan Nabi dengan berbagai macam budaya tersebut sekaligus bagaimana seharusnya sebuah hadis yang bersinggungan dengan budaya dipahami. 


\section{Dialektika Hadis terhadap Kebudayaan Arab}

Berbicara tentang model dialektika Nabi dengan budaya Arab tidak lepas dari peranan wahyu yang membimbing Nabi di dalam menghadapi masyarakat Arab. Meskipun Nabi dalam beberapa hal berijtihad di dalam tindakannya, namun wahyu senantiasa memantau perilaku Nabi sebagai wujud kemaksuman Nabi yang terpelihara dari kesalahan-kesalahan. Dalam penjelasan dialektika Nabi dengan budaya ini, penulis mengadopsi teori Ali Sodikin yang menyatakan bahwa dialektika Al-Qur'an dan budaya Arab terbagi menjadi tiga bentuk, yakni tahmil, taghyir, dan tahrim.

Nabi, dengan bimbingan al-Qur'an, membangun tatanan masyarakat yang sudah berbudaya tanpa menghilangkan secara total kebudayaan yang sudah berlaku. Metode Nabi dalam membangun masyarakat bisa dijadikan kerangka berpikir untuk membentuk masyarakat yang ideal. Di samping itu, juga dapat digunakan untuk memilah mana ajaran yang fundamental dan yang instrumental. Ajaran fundamental yang dimaksud adalah ajaran pokok yang merupakan nilai-nilai universal dari ajaran al-Qur'an dan sunnah yang harus diberlakukan di manapun dan kapanpun dan tidak tunduk pada sistem sosial dan adat istiadat yang berlaku. Sedangkan ajaran instrumental merupakan bentuk-bentuk ajaran yang dibangun dengan menggunakan simbol budaya sebelumnya. Simbol budaya dapat dipahami sebagai instrumen dalam mengimplementasikan ajaran fundamental alQur'an.

Penggunaan simbol budaya oleh Nabi sebagai penjelas al-Qur'an merupakan bukti bahwa Tuhan menggunakan pendekatan budaya dalam menurunkan risalah-Nya. Simbol budaya yang digunakan di sini bukanlah tujuan inti dari risalah tersebut, tetapi menjadi media yang menghubungkan antara Tuhan yang mengirimkan pesan dengan masyarakat Arab yang menerima pesan. Dalam teori komunikasi, efektifitas komunikasi dapat terjadi apabila antara pihak yang berkomunikasi menggunakan media yang bisa dipahami keduanya. (Sodiqin 2008: 114) Salah satu contohnya adalah 
hadis tentang apresiasi Nabi terhadap bahasa Arab: Diceritakan dari Ibnu Abbas R.A bahwasanya Rasulullah bersabda, "Cintailah bahasa Arab karena tiga hal; karena saya orang Arab, al-Qur'an berbahasa Arab dan perkataan ahli surga di surga nanti adalah bahasa Arab"(HR Al-Thabarani) (S. bin A. A. al-Q. Al-Thabarani 1983)

Hadis ini diriwayatkan oleh Imam Al-Thabarani, Imam Al-Baihaqi dan Al-Hakim. Tetapi hadis ini menurut Al-Dzahabi adalah hadis maudhu'. Terlepas dari penilaian para ulama tentang hadis tersebut, jika memang hadis ini benar-benar dari Rasulullah, maka tentu saja bahasa Arab bukanlah menjadi tujuan risalah Nabi. Tetapi bahasa Arab digunakan oleh Nabi sebagai medium bahasa untuk menyampaikan pesan ilabiah sebagaimana digunakan Allah dalam menurunkan al-Qur'an dengan bahasa Arab.

Terdapat tiga bentuk dialektika al-Qur'an dan budaya Arab. Pertama, tahmîl (adoptive complement) atau sikap yang mengapresiasi dan membiarkan berlakunya sebuah tradisi. Sikap ini ditunjukkan oleh adanya ayat-ayat alQur'an dan praktik hadis Nabi yang menerima dan melanjutkan tradisi yang sudah ada serta menyempurnakan aturannya. (Sodiqin 2008) Salah satu contohnya adalah sistem perdagangan. Dalam masyarakat Arab, tradisi jual beli, utang-piutang dan gadai-menggadai sudah berlaku kuat dalam masyarakat. Dengan kata lain, mereka sudah memiliki sistem ekonomi yang mapan dan diakui keberadaannya.

Dalam beberapa literatur hadis, Nabi memberikan pesan-pesan teknis dan etik dalam berdagang. Praktik perdagangan tetap dibiarkan tetap berlaku sesuai dengan adat istiadat masyarakat setempat. Salah satu contoh arahan Nabi dalam berdagang adalah larangan berdagang dengan cara yang zalim; bertransaksi dengan menggunakan pencatatan; bertransaksi dengan amanah dan jujur dan toleran dalam berakad. Dalam sebuah hadis Rasulullah bersabda, "Allah merahmati seseorang yang 'murah hati' ketika menjual, membeli dan menagih hutang." (HR Bukhari). (M. bin I. AlBukhari 1987)

DINIKA, Volume 4, Number I, January - April 2019 
Dalam kesempatan yang lain, Nabi juga sangat mengapresiasi orang yang mau berusaha dengan hasil kerjanya sendiri dengan bersabda, "tidak ada makanan yang lebih baik dimakan oleh seseorang kecuali ia memakan dengan hasil usahanya sendiri” (HR al-Bukhari). Dari awal, dijelaskan bahwa masyarakat Arab memiliki sistem ekonomi yang sudah mapan dan mayoritas pencarian nafkah orang Arab adalah dengan berdagang.

Contoh lain adalah sikap akomodatif Nabi terhadap beberapa tradisi yang sudah mengakar di masyarakat seperti menabuh rebana. Kaum Anshar memiliki tradisi mengadakan iring-iringan hiburan ketika acara penikahan. Dalam sebuah riwayat, Aisyah mengawinkan seorang wanita dengan sahabat Anshar kemudian dia ditanya oleh Rasulullah, "Tidakkah kaliah memiliki hiburan untuk pengantin? Sesungguhnya kaum Anshar itu suka hiburan". (A. Q. S. bin A. Al-Thabarani, n.d.)

Nabi juga menganjurkan agar dalam pernikahan diiringi tabuhan rebana untuk mengumumkan pernikahan. Diceritakan dari Aisyah r.a. ia berkata, Rasulullah bersabda, "Umumkanlah pernikahan, laksanakanlah di masjid, serta tabuhlah rebana serta adakanlah walimahan walau dengan seekor kambing" (Al-Bushiri, n.d.)

Sebagaimana dijelaskan di awal, tradisi menabuh rebana yang terkenal mengakar dalam masyarakat Anshar dan diakomodasi oleh Nabi bukanlah tujuan inti dari risalah Nabi, tetapi Nabi menggunakan medium adat istiadat masyarakat Arab untuk menyebarkan misi Nabi yakni mengumumkan pernikahan ke khalayak ramai bahwa kedua mempelai sudah sah menjadi pasangan suami istri.

Dari beberapa contoh di atas, menurut hemat penulis, Nabi menghargai tradisi yang sudah mengakar di kalangan masyarakat Arab pra-Islam, tetapi dengan catatan tradisi tersebut merupakan tradisi yang positif dan tidak bertentangan dengan risalah Nabi.

Kedua, taghyîr (Adoptive-reconstructive) yang berarti menerima tradisi Arab tetapi memodifikasinya dengan sedemikian rupa sehingga karakter 
dasarnya berubah. Nabi tetap menggunakan simbol-simbol pranata yang ada tetapi praktik yang ada di dalam tradisi tersebut disesuaikan dengan ajaran Islam sehingga karakter aslinya berubah. (Sodiqin 2008: 127)

Salah satu contohnya adalah tradisi akikah. Dalam tradisi masyarakat Arab Jahiliyyah terdapat tradisi akikah. Dalam tradisi Arab Jahiliyyah, jika ada seorang anak baru lahir, maka orang tuanya menyembelih kambing dan melumuri kepala anak yang baru lahir dengan darah kambing tersebut. Tradisi ini dilanjutkan oleh Nabi dengan mengubahnya dengan tradisi yang sesuai dengan risalah Nabi sebagaimana tercermin dalam hadis berikut: Dari 'Aisyah, ia berkata, "Dahulu orang-orang pada masa jahiliyah apabila mereka berakikah untuk seorang bayi, mereka melumuri kapas dengan darah akikah, lalu ketika mencukur rambut si bayi mereka melumurkan darah tersebut pada kepalanya". Maka Nabi bersabda, "Gantilah darah itu dengan minyak wangi” (HR Ibnu Hibban). (Al-Tamimi 1999)

Buraidah berkata: "Dahulu kami di masa jahiliyah apabila salah seorang di antara kami mempunyai anak, ia menyembelih kambing dan melumuri kepalanya dengan darah kambing itu. Maka setelah Allah mendatangkan Islam, kami menyembelih kambing, mencukur (menggundul) kepala si bayi dan melumurinya dengan minyak wangi." (HR. Abu Dawud)

Dalam hadis di atas, jelas sekali bahwa Nabi tetap menggunakan tradisi akikah yang merupakan bagian dari pranata sosial Arab pra-Islam sebagai bagian penting dalam ajaran Islam. Tradisi mengusap kepala bayi dengan darah diubah menjadi dengan mengusap kepala bayi dengan minyak Za'faran. Secara praktik, Nabi tidak banyak mengubah tradisi tersebut, tetapi yang diubah adalah pengusapan darah di kepala bayi karena darah dalam ajaran Islam hukumnya najis.

Ketiga, tahrim (Destructive) atau sikap penolakan keberlakuan sebuah tradisi masyarakat Arab jahiliyah yang dipandang negatif dan banyak mudaratnya. Pelarangan tersebut juga dibarengi dengan ancaman bagi 
yang melakukannya. (Sodiqin 2008: 124) Contohnya adalah budaya minum khamar di kalangan para sahabat sebelum masuk Islam, judi dan praktik riba, mengubur bayi perempuan yang masih hidup. Tradisi-tradisi tersebut sudah mengakar dalam kalangan masyarakat Arab.

\section{Pandangan para Pakar Terhadap Budaya dalam Hadis}

Imam Syah Waliyullah Addahlawi menyatakan bahwa hadis yang dikumpulkan dalam kitab hadis terbagi menjadi dua bagian. (Al-Dahlawi 2005: 223-224) Pertama, hadis yang disampaikan Nabi dalam kapasitasnya sebagai penyampai risalah (litablìgh al-risâlah). Salah satu contohnya adalah pengetahuan tentang ahkirat, dunia malaikat. Pengetahuan ini mutlak berasal dari wahyu. Contoh lain adalah syariat-syariat yang sebagian bersumber dari wahyu dan sebagian yang lain bersumber dari ijtihad Nabi, meskipun demikian, ijtihad Nabi sejajar dengan wahyu karena Allah menjaga Nabi dari kesalahan-kesalahan. Masuk juga dalam kategori ini penjelasan Nabi tentang akhlak baik dan yang buruk serta penjelasanpenjelasan keutamaan sebuah amal dan etika-etika bekerja.

Kedua, hadis-hadis yang disampaikan adalah hadis yang bukan dalam rangka penyampaian risalah. Al-Dahlawi mengutip hadis riwayat Muslim: Sesungguhnya saya manusia biasa, apabila saya memerintahkan kalian dengan urusan agama kalian, maka ambillah. Dan apabila saya menyuruh sesuatu dari pendapatku pribadi, maka saya adalah manusia biasa.

Salah satu contohnya adalah metode pengobatan Nabi dan kebiasankebiasaan Nabi dan bukan ibadah. Dari pembagian ini Addahlawi nampak menyatakan bahwa ada sebagian hadis yang terdapat dalam kitab-kitab hadis yang sebenarnya tidak serta merta berlaku secara paten dalam kehidupan seorang muslim. Salah satu contoh kasusnya adalah bekam. Di masa sekarang, beberapa pengobatan alternatif mengklaim bekam sebagai metode pengobatan Nabi dan menganggapnya sebagai ibadah sehingga orang yang menolak bekam rentan dianggap mungkir al-sunnah. Jika 
mengikuti pendapat Addahlawi, seseorang yang menolak berobat dengan bekam dan memilih berobat ke dokter misalnya tidak akan tergolong dari anggapan mungkir al-sunnah. Sebab yang dituju Nabi adalah berobat dari penyakit dengan media obat apapun, termasuk bekam. Oleh sebab itu, perlu metode pemahaman hadis-hadis yang berkaitan dengan budaya dan tradisi lokal Arab.

Ibnu Asyur mejelaskan bahwa ada hubungan erat antara hukum syar'i dengan 'urf yang juga merupakan bagian dari budaya. Ibnu Asyur menjelaskan bahwa hukum Islam yang dibawa Nabi haruslah menjadi hukum yang universal, karena Islam mengklaim dirinya bisa diterapkan di segala zaman dan tempat. (Audah 2013: 104); (Asyur 2001: 317)

Berdasarkan maksud universalitas syariat Islam ('umûm al-syarỉab), Ibnu Asyur menyarankan agar menginterpretasi ulang riwayat-riwayat dari Nabi yang disabdakan dengan mempertimbangkan konteks kebudayaan Arab dan tidak memperlakukannya sebagai aturan yang mutlak dan final. Jika hukum Islam dikehendaki menjadi hukum universal, maka ia harus menjadi cocok dengan hikmah dan nalar yang dapat diterima oleh semua kalangan manusia, yang tidak berubah-ubah seiring waktu dan tempat.

Dalam kerangka ini, Ibnu Asyur menjelaskan hikmah terpilihnya Nabi di kalangan Arab, salah satunya adalah kecerdasan pemikiran, kekuatan hafalan, kelugasan peradaban dan perundangannya, serta sifat terisolasinya orang Arab dari peradaban, yang membuat mereka siap untuk "selalu berbaur dan berkumpul secara terbuka dengan orang lain, tanpa memiliki beban warisan permusuhan, seperti keadaan orang Persia, Roma dan Mesir". Kondisinya yang demikian, membuat daya tarik tersendiri bagi kalangan-kalangan luar Arab untuk mengetahui hukum tersebut karena tidak adanya warisan permusuhan orang Arab dengan negara manapun, sebab permusahan di kalangan Arab hanya terjadi dalam intern antar kabilah-kabilah Arab sendiri. (Asyur 2001: 319)

DINIKA, Volume 4, Number I, January - April 2019 
Selanjutnya Ibnu Asyur, memilah mana hukum yang universal berlaku di setiap waktu dan tempat dan mana yang bersifat lokal temporal yang terpengaruh oleh 'urf Arab. Ibnu Asyur menjelaskan bahwa di dalam hadis terdapat kaidah umum (qawaid al-âmmah) yang berlaku universal. Contohnya, hadis tentang menjaga diri, harta dan martabat, inna dimaakum wa amwalakum wa absyarakum 'alalikum haram. Selain itu ada juga hadis-hadis yang disabdakan dalam kasus-kasus tertentu seperti pelarangan penulisan sesuatu apapun termasuk perkataan Nabi kecuali al-Qur'an. Hikmah pelarangan penulisan tersebut menurut Ibnu Asyur tidak selayaknya dianggap kasus yang khusus dan berlaku universal. (Asyur 2001: 319-320)

Lebih rinci lagi, Ibnu Asyur menjelaskan gagasannya terhadap sejumlah riwayat hadis yang menurutnya harus dipilah antara yang universal dan lokal temporal. Berikut pernyataan Ibnu Asyur yang dikutip Jasser 'Audah,

"oleh karena itu, hukum islami tidak menyibukkan dirinya dengan menentukan jenis-jenis pakaian, rumah-rumah dan kendaraan. Maka, tidak disunnahkan seseorang mengendarai unta dalam bepergian, orang Mesir dan Iraq tidak dilarang mengendarai himar, begitu juga orang India tidak dinafikan karena meninggalkan mengendarai sapi. Jadi orang-orang muslim tidak butuh mencari-cari dalil kebolehan mengendarai anak sapi, dokar dan..... kita menegaskan bahwa adat suatu kaum tidak boleh dipaksakan kepada kaum yang lain sebagai aturan hukum. Kebiasaan atau adat suatu masyarakat tidak boleh juga dipaksakan kepada anggota masyarakatnya yang belum bisa menerimanya.... Metode interpretasi ini dapat menghilangkan banyak kebingungan yang dihadapi banyak ulama dalam mengungkap sebab di balik sejumlah larangan hukum islami... seperti larangan perempuan menyambung rambut, memisahkan antara gigi depan, atau menggambar tato. Makna sebenarnya dari larangan tersebut, menurut saya, ... bahwa larangan praktik-praktik itu disebut dalam hadis karena saat itu orang Arab menganggapnya sebagai tanda kurang sopan bagi kaum perempuan. Dengan demikian, pelarangan 
hal-hal tersebut sebenarnya bermaksud untuk menahan dorongan kejahatan yang khas zaman itu ... mirip dengan hal itu adalah apa yang kita baca dalam al-Qur'an: "wanita beriman agar mengulurkan jilbabnya ke seluruh tubuh mereka" (Q.S 33:59) ...ini adalah legislasi yang mempertimbangkan tradisi Arab, sehingga tidak perlu diterapkan kepada mereka yang tidak memakai busana seperti itu... " (Asyur 2001: 322-324)

Inti dari pemikiran Ibnu Asyur di atas adalah menekankan interpretasi ulang terhadap hadis-hadis yang mempertimbangkan konteks Arab dari pada menjadikannya sebagai aturan hukum yang final. Menurut Jasser Audah, Ibnu Asyur memahami riwayat-riwayat di atas dalam rangka tujuan-tujuan moral dasar, ketimbang norma yang diterapkan untuk dirinya sendiri. Pendekatan seperti ini memungkinkan fleksibilitas dalam penerapan hukum Islami pada budaya-budaya lokal, khususnya non-Arab. (Audah 2013: 107) Inilah yang sering menjadi pertentangan para ulama mengenai tradisi-tradisi lokal yang jarang dibahas secara serius dalam literatur-literatus hadis.

Senada dengan pendapat Ibnu 'Asyur, Ali Mustafa Yaqub dalam buku Cara Benar Memahami Hadis menyajikan bab khusus tentang budaya arab dalam hadis. Ia memulai pembahasannya dengan mengutip surat al-Hasyr ayat 7 yang artinya "Apa yang diberikan Rasul kepadamu kama ambillah, dan apa yang dilarangnya bagimu maka tinggalkanlah"

Ali Mustafa Yaqub menjelaskan bahwa dalam ayat tersebut Allah memerintahkan kaum mukminin untuk mengambil apa-apa yang datang dari Rasulullah, baik dalam hal syariat dan agama atau dalam urusan dunia berupa budaya dan muamalah. Hal ini karena lafadz ' $m \hat{a}$ ' pada ayat di atas mengandung arti umum. Apa saja yang datang dari Rasulullah maka kita wajib mentaatinya. Tetapi, ayat ini tidak selamanya bersifat umum, karena ada ayat lain yang berasal dari Rasulullah yang mengkhususkan keumuman ayat tersebut. (Yaqub 2014: 96)

DINIKA, Volume 4, Number I, January - April 2019 
Salah satu contohnya adalah riwayat tentang mengawinkan kurma. Dalam Shahih Muslim terdapat riwayat berikut: Ketika Nabi Muhammad tiba di Madinah, mereka sedang mengawinkan kurma. Mereka katakan sebagai penyerbukan terhadap kurma (agar dapat berbuah). Kemudian Nabi bersabda, "Apa yang sedang kalian lakukan?” mereka menjawab, "kami biasa melakukannya". Nabi berkata, "Kalian dapat pertimbangkan seandainya tidak melakukannya, maka hal itu lebih baik". Kemudian pada sahabat tidak melakukan (penyerbukan)nya lagi kemudian tanaman kurma menjadi kurang baik dan berkurang. Mereka kemudian mengadu kepada Rasulullah dan Rasulullah bersabda, "Sesungguhnya saya adalah manusia biasa, jika saya memerintah kalian sesuatu yang berkaitan dengan agama kalian, maka amibillah, dan jika saya memerintahkan sesuatu yang berasal dari pendapatku, maka saya adalah manusia biasa" (HR Muslim) (AlNisaburi, n.d: 95)

Menurut Yaqub, Q.S al-Nahl [59]:7 di atas tidak bisa dipahami secara umum bahwa segala sesuatu yang berasal dari Nabi wajib diikuti, karena ada hadis-hadis Nabi yang mengkhususkannya sebagaimana yang disebut di atas. (Yaqub 2014: 98) Imam Muslim pun menempatkan hadis ini di kitab shahihnya dalam subbab yang berjudul Bâb Wujûbi Imtitsâli mâ Qâlahû Shallallâhu 'alaibi wa Sallam Syar'an Dûna Mâ Drakarahû min Ma'âyisy al-Dunyâ 'Alâ Sabîl al-Ra'yi (Bab wajibnya mengikuti sabda Nabi yang berkaitan dengan syariah, bukan pernyataan beliau tentang kehidupan dunia dan pendapatnya). (Al-Nisaburi, n.d.: 95) Dari penjelasan Imam Muslim tentang judul subbabnya ini bisa diambil kesimpulan bahwa memang ada hadis Nabi yang berkaitan dengan syariah yang wajib diikuti dan ada juga hadis-hadis yang berkaitan dengan budaya, tradisi dan pendapat Nabi yang boleh diikuti atau tidak diikuti. 


\section{Memahami hadis Nabi yang Berkaitan dengan Budaya}

Ada beberapa pendekatan yang ditawarkan oleh beberapa pemikir kontemporer di antaranya adalah pendekatan sosiologis, historis, psikologis, dan pendekatan kontekstual. Terdapat beberapa contoh mengenai hal tersebut: Pertama, hadis tentang pakaian Nabi. Di antara beberapa contoh hadis yang terkait dengan budaya Arab adalah jenis pakaian. Di dalam tradisi Arab, terdapat beberapa jenis baju yang dipakai, di antaranya adalah: iøâr (kain bawahan sejenis sarung), qamis (gamis atau kemeja), sirwâl (celana panjang), tubbân (celana pendek), qubbâ' (pakaian luar), tsaub (pakaian biasa), ridâ' (kain atasan sejenis selandang), burmus (sejenis mantel yang bertudung kepala), kisa' (pakaian biasa), bullah (pakaian setelan), 'imâmah (surban), qalansuwah (tutup kepala sejenis peci) dan lain-lain. (Yaqub 2014: 99) Namun, yang sering diklaim sebagai Sunnah Nabi adalah surban, hingga ada yang berpendapat siapa yang bersurban adalah umat Nabi sedang yang tidak pernah bersurban bukan umat beliau. Padahal, Rasulullah juga mengenakan jenis pakaian lain selain surban, misalnya kain bawahan sejenis sarung, gamis dan kain atasan sejenis selendang. (Yaqub 2014: 100) Perbedaan di antara kita dengan orang-orang musyrik adalah surban yang dipakai atas kopiah (HR Abu daud dan al-Tirmidzi) (Al-Sijistani, n.d: 95).

Yaqub dalam menjelaskan hadis ini menyatakan bahwa tidak ada seorang ulama pun yang berpendapat bahwa mengenakan surban itu wajib, sehingga jika tidak mengenakan surban tidak durhaka dan tidak berdosa kepada Allah. Sebab pakaian sejenis surban, kain atasan sejenis selendang, tutup kepala, gamis dan lainnya bukan termasuk urusan agama yang wajib diikuti oleh setiap muslim. Namun semua itu dikategorikan sebagai budaya Arab yang dikenakan bangsa Arab baik yang muslim maupun nonmuslim pada masa Nabi. Oleh karenanya, ia boleh diikuti dan boleh tidak diikuti. seorang mukmin diperintahkan untuk mendahulukan yang kanan dan tidak berlebihan dalam bersurban dan inilah yang diperintahkan dan aturan agama dalam bersurban. (Yaqub 2014: 101-102)

DINIKA, Volume 4, Number I, January - April 2019 
Di samping itu, setiap negara memiliki pakaian kehormatan yang berbeda-beda. Selama seseorang mengenakan penutup kepala seperti ini, maka ia telah mengikuti sunnah Rasulullah., inilah yang dimaksud dengan universalitas Islam yang tidak hanya berlaku bagi orang Arab tetapi juga bagi seluruh penduduk dunia semuanya. Islam tidak pernah memerintahkan kepada kaum muslim untuk mengenakan jenis pakaian tertentu, bentuk yang khusus atau model tertentu, tetapi hanya menyuruh hijab secara Islami, misalnya: menutupi aurat, bentuk longgar tidak sempit, tidak transparan, pakaian laki-laki tidak menyerupai pakaian perempuan dan sebaliknya. Apabila syarat-syarat ini terpenuhi, masyarakat muslim boleh memilih bentuk dan model pakaiannya. (Yaqub 2014: 102-103)

Kedua, hadis tentang larangan bepergian tanpa mahram. Dari Ibnu Umar R.A. sesungguhnya Nabi Muhammad bersabda, "janganlah perempuan bepergian sejauh perjalanan tiga hari kecuali disertai mahram" (HR al-Bukhari). (M. bin I. Al-Bukhari, n.d.: 43, Hadis No 1086) Hadis semisal banyak diriwayatkan oleh para mukharrij hadis lain seperti Imam Muslim, Abu Daud, Ibnu Majah, al-Tirmidzi, Ibnu Hibban, Ibnu Khuzaimah.

Hadis ini menurut Abdul Muhsin al-Ubbad menjelaskan tentang keharaman perempuan bepergian tanpa mahram meskipun dalam kondisi yang tidak aman atau dalam kondisi aman dari fitnah. (Al-Ubbad, n.d.: 24) Sedangkan menurut Imam Nawawi, hadis tersebut dipahami oleh jumhur ulama sebagai laranngan perempuan bepergian yang bersifat sunnah atau mubah. Sedangkan bepergian bersifat wajib, para ulama berbeda pendapat. (Mustaqim 2008: 65)

Abdul Mustaqim dalam menjelaskan hadis ini, menyatakan bahwa belum ditemukan sabab al-wurud hadis ini. Ia melanjutkan bahwa besar kemungkinan bahwa hadis ini dilatar belakangi oleh kondisi sosiologishistoris masyarakat Arab saat itu, yakni Nabi mengkhawatirkan keselamatan perempuan. Di samping itu sistem nilai yang ada pada saat 
itu, perempuan dinilai tabu dan kurang etis jika bepergian jauh sendirian. (Mustaqim 2008: 66) Dengan penjelasan ini menjadi jelas bahwa hadis ini berkaitan erat dengan kultur lokal Arab di mana saat itu perempuan terancam keselamatannya jika bepergian jauh sendirian tanpa mabram. Jika zaman telah berubah, jarak jauh sudah tidak lagi menjadi masalah serta didukung sistem keamanan yang menjamin keselamatan perempuan, maka tidak apa-apa perempuan bepergian sendirian untuk menuntut ilmu, pergi haji dan bekerja. (Mustaqim 2008: 67) pendapat ini didukung oleh hadis prediktif Nabi dalam Shahih al-Bukhari.

Dari Adi bin Hatim ia berkata, suatu ketika saya ada di sisi Nabi. Tibatiba datanglah seorang laki-laki yang mengadukan tentang kemiskinan, kemudian datang yang lain mengadukan tentang kehabisan bekal di jalan. Kemudian Nabi bersabda, "wahai Adi, tahukah kamu negeri Hirah?" saya menjawab, "belum Nabi", Nabi bersabda, "saya (Nabi) telah diberitahu tentang negeri itu, jika umurmu panjang, niscaya kamu akan melihat perempuan penunggang unta yang bepergian dari Hirah menuju Ka'bah sehingga ia thawaf di Ka'bah dan ia tidak takut kepada siapapun kecuali kepada Allah " (HR al-Bukhari). (M. bin I. Al-Bukhari, n.d: 197, Hadis No 3595).

Hadis ini menunjukkan prediksi Nabi tentang kejayaan Islam di seantero dunia dan menunjukkan kebolehan perempuan bepergian sendirian jika dalam kondisi aman. Pendapat ini dinyatakan oleh Ibnu Hazm yang dikutip oleh Yusuf al-Qaradhawi. (Mustaqim 2008: 69)

Ketiga, Hadis tentang memakai sandal dalam salat. Dikisahkan dari Ya'la bin Saddad bin Ausdari ayahnya ia berkata, bersabda Rasulullah. "Bedailah orang-orang Yahudi, sesungguhnya mereka tidak salat dengan sandal mereka dan sepatu mereka"(HR Abu Daud) (Al-Sijistani, n.d: 176, Hadis No 652).

Hadis ini dinilai shahih oleh Albani. Abu Abdurrahman al-Bassam menyatakan bahwa memakai sandal dan sepatu atau sandal merupakan 
sunnah Nabi yang patut untuk dilestarikan. Ia mengutip hadis Nabi yang memerintahkan para sahabat untuk memakai sandal dan atau sepatu ketika shalat. Said bin Yazid bertanya kepada Anas bin Malik, "Apakah Rasulullah salat dengan kedua sandalnya supaya ditiru?" Anas menjawab, "iya! Nabi salat dengan kedua sandalnya dan ini merupakan Sunnah Nabi yang suci." (Al-Bassam 2006: 163)

Abdurrauf al-Minawi menjelaskan bahwa sebagian ulama salaf mengambil makna dhahir hadis. Pendapat ini juga didukung oleh Imam Syafi'i dalam qoul qadimnya, sedangkan dalam qoul jadid-nya, ia berpendapat sebaliknya dengan mendasarkan pada syariat Nabi Musa yang melepas sandal ketika dalam salat, sebagaimana tercantum dalam al-Quran surat Thaha [20]:12. Imam al-Iraqi menyatakan bahwa hikmah memakai sandal ketika salat di antaranya adalah membedai orang-orang Yahudi; kekhawatiran menyakiti orang lain dengan dilepasnya sandal, atau khawatir dicuri oleh maling atau dibawa hewan kemudian terkena najis. Ibnu Baththal menyatakan bahwa kebolehan ini dipahami dalam kondisi sandal tidak najis. Sedangkan al-Qusyairy menyatakan bahwa ini merupakan rukhsah, bukan anjuran (mandub) karena tidak masuk dalam kategori perbuatan yang harus dikerjakan ketika shalat. (Al-Munawi, n.d.: 431); (Yaqub 2014: 125-126)

Hadis ini tentu sangat sulit jika diamalkan pada masa sekarang, sebab kondisi masjid pada masa sekarang sangat berbeda dengan masjid di zaman Rasulullah. Oleh karena itu, hadis ini merupakan salah satu hadis yang terikat dengan kondisi sosial masyarakat pada waktu itu di mana masjid bentuknya seperti sepetak tanah yang dikelilingi pagar atau dinding di bagian sisi-sisinya. Oleh karena itu, hadis ini menurut Yaqub hanya bisa diamalkan di masjid yang sama seperti masjid pada masa-masa Nabi, dan tidak bisa diamalkan pada masa sekarang. (Yaqub 2014: 124)

Dari beberapa penjelasan contoh di atas, hadis-hadis yang berkaitan dengan budaya lokal Arab selayaknya tidak langsung dicerna mentah- 
mentah tanpa adanya kajian mendalam tentang hadis tersebut. Sebab, secara faktual terdapat hadis-hadis yang berlaku dan terikat dengan konsteks sosial masyarakat Arab pada waktu hadis itu disabdakan oleh Rasulullah.

\section{Kesimpulan}

Nabi sebagai utusan Allah di dalam menyampaikan risalah ilahiyah melakukan interaksi dan dialog dengan budaya yang berkembang dalam masyarakat Arab. Dialog dengan budaya merupakan hal yang niscaya bagi siapa saja yang ingin membangun sebuah masyarakat yang ideal sebagaimana yang dilakukan oleh Nabi. Sebagian budaya yang berkembang di Arab diterima dengan baik oleh Nabi, sebagian lagi dimodifikasi dan sebagian yang lain diputus karena bertentangan dengan nilai-nilai risalah Nabi.

Dialog Nabi dengan budaya lokal Arab meniscayakan Nabi menggunakan media komunikasi kebudayaan yang dapat dicerna oleh masyarakat pada saat itu. Dalam tahap ini, Nabi menggunakan bahasa, pesan moral, serta aturan-aturan yang erat kaitannya dengan budaya yang berkembang serta sesuai dengan kebutuhan masyarakat. Hal ini terkadang menyebabkan sebagian hadis tidak bisa diterapkan secara langsung di dalam kehidupan masyarakat kontemporer yang memiliki kebudayaan dan setting sosial yang berbeda. Oleh karena itu, hadis-hadis yang berkaitan erat dengan budaya lokal Arab sepatutnya tidak langsung diterima sebagai sebuah hukum yang final, tetapi dikaji terlebih dahulu secara mendalam untuk diinterpretasikan ulang agar bisa diaplikasikan dalam kehidupan masyarakat kontemporer.

DINIKA, Volume 4, Number I, January - April 2019 


\section{Referensi}

Al-Bassam, Abu Abdirrahman. 2006. Tafsir al-Allam Syarah Umdab alAbkam. Kairo: Maktab al-Shahabah.

Al-Bukhari, Imam. n.d. "Shahih al-Bukhari Hadis No. 1865." CD alMakktab al-Syamilah al-Isdar al-Tasni.

Al-Bukhari, Muhammad bin Ismail. n.d. Al-Jami al-Murnad al-Shabih alMukbtashar min Umur Rasulillah Shallallau Alaibi wa Sallam wa Sunanibi Wa Ayyamih. Dar Thauq al-Najah.

. 1987. Al-Jami' al-Shabîh al-Mukhtashar. Beirut: Dar Ibn Katsir.

Al-Bushiri, Ahmad bin Abi Bakar. n.d. Ittihaf al-Khiyarah al-Mibrah, Kitab al-Nikah Juг 4. Software al-Maktabah al-Syamilah Edisi Ke-2.

Al-Dahlawi, Syah Waliyullah. 2005. Huijatullah al-Balighah. Beirut: Dar alJil.

Al-Munawi, Abdurrauf. n.d. Faidul Qadir Syarah al-Jami' al-Shaghir. Mesir: Al-Maktabah al-Tujjariyah al-Kubra.

Al-Nisaburi, Abu al-Husein Muslim bin al-Hajjaj bin Muslim. n.d. Al-Jami' al-Shabih al-Musamma Shabih Muslim. Beirut: Dar al-Afaq al-Jadidah.

Al-Sijistani, Abu Daud. n.d. Sunan Abu Daud. Beirut: Dar al-Kitab al-Arabi.

- n.d. Sunan Abu Daud. Beirut: al-Maktabah al-Ashriyyah.

Al-Tamimi, Muhammad bin Hibban bin Ahmad. 1999. Shabib Ibn Hibban Bitartib Ibn Balbab. Beirut: Muassasah al-Risalah.

Al-Thabarani, Abul Qasim Sulaiman bin Ahmad. n.d. al-Mu'jam al-Ausath. Kairo: Dar al-Haramain.

Al-Thabarani, Sulaiman bin Ahmad Abul al-Qasim. 1983. al-Mu'jamul Kabir. Maktabah al-'Ulum wal Hikam.

Al-Ubbad, Abdul Muhsin. n.d. "Syarah Sunan Abi Daud." Software alMaktab al-Syamilah.

Asyur, Muhammad Thahir bin. 2001. Maqashid al-Syariah al-Islamiyyah. Ardan: Dar al-Nafais.

Audah, Jasser. 2013. Al-Maqashid untuk Pemula (Terj). Edited by Ali Abdelmon'im. Yogyakarta: SUKA Press.

Mustaqim, Abdul. 2008. Ilmu Ma'anil Hadis Paradigma Interkoneksi. Yogyakarta: Idea Press. 
Nurdin, Ali. n.d. Quranic Society: Menelusuri Konsep Masyarakat Ideal dalam Al-Quran. Jakarta: Penerbit Erlangga.

Sodiqin, Ali. 2008. Antropologi al-Quran, Model Dialektika Wabyu dan Budaya. Yogyakarta: Arruz Media Grub.

Yaqub, Ali Mustafa. 2014. Cara Benar Memahami Hadis (Terj). Jakarta: Pustaka Firdaus. 